\title{
Online Collaboration between Israeli Palestinian Arab and Jewish Students: Fear and Anxiety
}

\author{
Manal Yazbak Abu Ahmad \\ Sakhnin College for Teacher Education \\ Israel \\ Elaine Hoter \\ Talpiot Academic College \\ Israel
}

\begin{abstract}
This study examines Israeli Palestinian Arab and Jewish students from five education colleges in Israel. Students worked collaboratively through a yearly online intercollegiate program. The research includes qualitative analysis of openended questions and ongoing reflective journals as well as quantitative analysis of pre and post questionnaires. The qualitative results revealed that students' initial apprehension about working with people from the other culture diminished at the end of the course. This change was backed up by the results of the t-test $(-4.38)$, which indicated that the perception of other participants in the group improved significantly among both Jewish and Israeli Palestinian Arab participants.
\end{abstract}

KEYWORDS: multicultural, online collaboration, minority culture, small group work, stereotype

Teacher Training and Multiculturalism

Virtual Friendship in the Outgroup Context

Multicultural Encounters and Collaborative E-learning

Methodology

Qualitative Findings

Quantitative Findings

Discussion

Implications

Limitations

Conclusion

References

Author Contact

The need for students from different cultures to meet and study together is an ideal held by many educators around the world. Segregation of cultures leads to stereotyping and bias. There have been numerous intervention projects in many countries to bring together students from different cultures, with various levels of success (Batson \& Ahmad, 2009; White \& Abu-Rayya, 2012). The internet has made intercultural collaboration more practical since educators are now able to bring people from different geographical areas together with almost no expense (Amir, 1969; Hasler \& Amichai-Hamburger, 2013; Helm, 2015; Salomon, 2013; Shonfeld, Hoter, \& Ganayem, 2013). 
In Israel, $20 \%$ of the population are indigenous Palestinian Israelis (Muslims, Christians, Druze, and Circassians), whose children study in Arabic-speaking schools using the same curriculum as the Hebrew-speaking schools, yet there is little connection between the pupils in the Arab and Jewish schools. This is due in part to the segregation in the educational system and to language issues, which can result in disagreements and differences in the context of the wider Israeli-Palestinian conflict (Maoz, 2011; Salomon, 2013; Yazbak Abu Ahmad, Dessel, \& Ali, 2018). This segregation leads to anxiety between the two groups, stereotyping, and prejudice (Amichai-Hamburger \& McKenna, 2006; Greenland, Xenias, \& Maio, 2012). A lack of contact between the Israeli Palestinian Arab and Jewish groups, particularly where there have been prior conflicts, leads to contact-related anxiety. The very existence of the Israeli Palestinian Arabs (outgroup, minority, or subculture) is often viewed as both a physical and political threat to the Jewish Israelis, the ingroup or what is considered by law as the mainstream dominant society (Shapira, Kupermintz, \& Kali, 2016; Shonfeld, Hoter, \& Ganayem, 2013; Žeželj, Ioannou, Franc, Psaltis, \& Martinovic, 2017).

This study, which was conducted in 2016-2017, focuses on a group of college students, Arab, Jewish, secular, and religious, who were training to be English teachers in five Israeli teaching colleges. The complexities of mainstream Israeli society (Jewish secular and religious) are extremely difficult to navigate. For instance, the social differences between secular and religious Jewish Israelis prevent the adoption of a state constitution. The existence of another group, Israeli Palestinian Arabs, further compounds the complexities due to the political, religious, social, and traditional differences of each group. The course that this research focuses on is the first opportunity for many of the students to work with someone from a different culture.

For this study, we researched the year-long English course, "Exploring Cultures through Minority Literature," which is one of the courses offered by the Technology, Education and Cultural Diversity (TEC) Center. The online course is team-taught using the TEC model, which involves collaborative online learning for small groups from different cultures (Hoter, Shonfeld \& Ganayem, 2009, 2012). It enables students from different cultures, religions, and backgrounds, often in conflict, to work together online. In this model, students from different cultures work online over a period of a year in small multicultural groups. The communication between the participants is initially through writing texts, then by listening to one another, talking, meeting through avatars, and finally communicating face to face. The collaboration required also becomes more demanding from task to task (Hoter et al., 2009).

This study began after the course had been offered for five years. The themes of the course have been changed over the years to represent the various cultures enrolled, and the literary material has been modified to represent issues pertinent to the cultures of course participants. In particular, the texts and materials studied in this research focused primarily on women's literature, written in English, by Arab/Palestinian and Jewish writers. The texts discuss both Arab/Palestinian and Jewish cultural themes and issues. The 115 students were divided into 20 mixed groups, consisting of one or two students from each college. The students interacted and worked collaboratively online on different assignments throughout the course and had one face-to-face meeting during the course towards the end of the first semester. 
The students worked online both synchronously (all students met online at the same time and joined the interactive online session) and asynchronously (the students could work at their convenience). The students submitted their assignments collaboratively in mixed small groups composed of students from all the colleges. They were required to participate in all parts of the course, including 10 online synchronous meetings throughout the year in which they heard lecturers and participated in assignments. All of the synchronous sessions, including lectures and student interactions, were recorded and archived on the course site and made available to the students. The students carried out collaborative assignments that were guided by the instructors in their small mixed groups between the online meetings. In each assignment, a different student took on the responsibility of moderating the small group and the discussions leading to the completion of the assignment.

The purpose of this study was to examine student attitudes to the other group. In other words, it looked at how the Jewish students (the ingroup both religiously and secularly) viewed the Palestinian Arab students and their religion and culture (the outgroup) and, vice-versa, how the Palestinian Arabs viewed the Jewish students. In addition, the study examined the process the students went through when they took a multicultural online collaborative course, as well as the possible reasons for any changes in attitudes.

\section{Teacher Training and Multiculturalism}

Israel's society presents a unique challenge to educators. Whilst multicultural in theory, it is fragmented in practice. Israeli Palestinian Arabs and Jewish Israelis reside in close physical proximity, yet remain distant and removed. In fact, the $20 \%$ Israeli Palestinian Arab minority is largely invisible to the Jewish population (Horencyzk \& Tatar, 2004; Salomon, 2013). Thus, any attempt to move from a pluralistic society, made up of separate cultures without mutual recognition, to a multicultural society based on mutual respect must include elements of multicultural education (State Comptroller Special Report, 2016). Multicultural education has evolved from a tool in the hands of a dominant majority seeking to assimilate a minority in the 1960 s to a celebration and acceptance of a society's diversity (Banks, 2009; Hill, 2007). This progression is seen by Hill (2007) in a number of stages, starting from a monocultural perspective, then moving to tolerance of cultural difference. Today, research shows the importance of developing social and emotional learning skills, pointing to the importance of empathy (Shapira et al., 2016). Our knowledge from the new disciplinary area of cultural neuroscience leads us to an understanding of how we can adapt and teach the area of multiculturalism dynamically where context leads to change, enabling the students to develop a multicultural mind (Nguyen-Phuong-Mai, 2017).

In his book Orientalism, Said (1978) discusses the binary opposition of the privileged "Self" versus the weak "Other." This binary opposition is reflected in different contexts using different terms: majority/minority, dominant/targeted, ingroup/outgroup, or simply self/other. Since Israeli classrooms are a microcosm of a variegated society, educators feel that it is essential for teachers to deal with these binary oppositions. 
Causey et al. (2000) speak of the need to enable intercultural sensitivity and learning for future teachers. It is no less imperative that Israeli teachers develop such sensitivity to "the other," as called for by Yogev $(2001$, p. 372) in his insistence that there be a teacher training reform that focuses on multicultural education. Since 2015, the Ministry of Education and the Higher Council have required pre-service students to take a course in multicultural education in order to complete their teaching degree. However, a recent special report commissioned by the state comptroller pointed to the lack of systematic multicultural education available in Israel (State Comptroller Special Report, 2016). The special commission felt that requiring students to take a multicultural course was not sufficient. They recommended that the requirement be regulated to ensure that there is a clear message of no discrimination and no prejudice within the Israeli democracy (State Comptroller Special Report, 2016).

In a study of student teachers who had received multicultural theoretical courses, Smith (2000) found that student teachers' views of multicultural education seemed not to be significantly influenced by either the course or the multicultural objectives infused throughout the teacher education program. According to his findings, the essential element is experiences with diverse groups. This can make a difference to a student teacher's conception of multiculturalism. Therefore, student teachers must also have opportunities to interact with students from diverse backgrounds (Valentine, 2006; Yazbak Abu Ahmad \& Yahav, 2014). Only when teacher education programs take some responsibility for preventing the "development of negative attitudes" towards students who represent "the other" (either from a cultural, ethnic, or even special needs point of view) can teachers begin to serve as change agents for acceptance and sensitivity in addressing diversity (Jobling \& Moni, 2004).

Thus, a truly multicultural online course will need to infuse the multicultural model suggested by Banks $(2001,2009)$ that calls for teachers to obtain the skills and knowledge needed to function effectively in different educational and cultural contexts. The curriculum should be based on target knowledge and skills that deal with diversity through learning about topics such as home, identity, family, and food, as well as integrating the opportunity for interaction with "the other" as called for by Said (1978), Smith (2000), and Valentine (2006).

\section{Virtual Friendship in the Outgroup Context}

Educational research suggests that cross group friendships with outgroup members, that is, with those from a different racial, ethnic, or religious social identity group, can reduce intergroup anxiety (Stephan \& Stephan, 1985; Shapira et al., 2016). The apprehension felt before participating and engaging with the outgroup has the potential to poison intergroup encounters. Once this anxiety and apprehension is reduced, there can be an improvement in intergroup relations (Turner, Tam, Hewstone, Kenworthy, \& Cairns, 2013; Turner \& Cameron, 2016; Pettigrew \& Tropp, 2008; Žeželj et al., 2017). Walther and Carr (2010) suggest that when members of a virtual team have less in common, they unite through collaboration on their task, and this facilitates identification with a superordinate group. Studies of Protestant and Catholic youth in 
Northern Ireland (Abrams, Hogg, \& Marques, 2005), White and Black students in South Africa (Aberson, Shoemaker, \& Tomolillo, 2004), and Latino and White youth (PageGould, Mendoza-Denton, \& Tropp, 2008) and African Americans and Latinos (Aberson, Shoemaker, \& Tomolillo, 2004; Hamm, Brown \& Heck, 2005) in the U.S. all assert the significant positive effects of cross group friendships and their ability to decrease bias and cultivate interactions.

In his contact hypothesis, Allport (1954) mentions four conditions for successful intergroup contact: equality between participants, a joint goal, collaboration, and institutional support. Pettigrew (1998) adds the condition of the potential for friendship as an important fifth component to the original contact hypothesis. Accordingly, friendship would seem to be an important component with respect to the Israeli/Palestinian conflict (Maoz, 2002). One study found that participation in an intergroup dialogue course led to the development of friendships between Arab and Jewish college students (Dessel \& Ali, 2012). Another study in Croatia, Serbia, and Cyprus showed that virtual meetings led to more positive feelings towards rival outgroups. (Žeželj et al., 2017). These relationship bonds compared favorably with face-to-face contacts, testifying to the added value of online ties (Žeželj et al., 2017).

\section{Multicultural Encounters and Collaborative E-learning} providing:

Online collaborative learning theory (OCL), is described by Harasim (2012) as

a model of learning in which students are encouraged and supported to work together to create knowledge: to invent, to explore ways to innovate, and, by so doing, to seek the conceptual knowledge needed to solve problems rather than recite what they think is the right answer. (p. 90)

OCL theory is important because it is a basic component that encourages the learners to be active and engaged, and from there they can develop learning and knowledge construction.

Student teachers should have "more current technological experiences, models and learning tools" in order to be competent teachers (Wallace \& Rogers, 2011, p. 33). The use of technology would not only augment fluency in group discussions, easing possible tensions or feelings of insecurity, but would also benefit the student teachers who would be using such tools in their future classrooms (Yazbak Abu Ahmad \& Yahav, 2014).

The benefits of collaborative e-learning for English as a Foreign Language (EFL) or English as a Second Language (ESL) students have been extensively documented. Razak and Asmawi (2004) and Foroutan and Noordin (2012) discuss the benefits of dialogue journals and email technology in their ESL courses, emphasizing the fact that meeting the requirements of real communication in a social context enhances language fluency. These two technological tools also require students to invest effort in clear and organized modes of expression. Both Bollati (2002) and Foroutan and Noordin (2012) add important aspects of online learning - that of developing a sense of community, where students feel closer as a result of the back-and-forth nature of the communication, 
and the fact that students who might be reluctant to speak in a classroom (because of shyness or lack of language proficiency) can express themselves with fewer anxieties. Many researchers point to the fact that online learning extends the learning time and place. In other words, the students' learning is no longer bound by the classroom meeting, but can continue at other times in other venues (Hoter, Shonfeld, \& Ganayem, 2012; Hasler \& Amichai-Hamburger, 2013). In addition, online learning is student-centered in that students control their learning and participation. A number of educators have developed and successfully implemented collaborative projects in which two classes in different geographical locations (sometimes different countries) are broken down into small virtual groups and assigned joint projects (Dewiyanti, Brand-Gruwel, Jochems, \& Broers, 2007; Helm, 2015; Hoter, 2006).

Walther and Bunz (2005) show that the optimal online group size is six and have found a number of rules that, if followed, improve online collaborative learning in virtual groups. These include replying promptly, starting assignments immediately, and making a timeline. Mollov (2006), in a study of emailing versus face-to-face conversation, examines how the medium of email can "defuse" intercultural differences regarding demand for direct answers, the policy of avoidance, or differences in wait-time, and therefore can enable a smoother, less tension-fraught intercultural dialogue. Walther et al. (2015) assert that online collaborative learning between Israeli Palestinian Arab and Jewish students in Israel can change attitudes and biases under conditions stipulated in the TEC Model, which is an extension of the contact hypothesis using computers in education as a context area (Hoter, Shonfeld, \& Ganayem, 2012). However, when it comes to analyzing and seeing the effects of programs for meetings between conflicting groups, the results are mixed. Significant findings are difficult to obtain when using standard questionnaires that are not sensitive enough to the differences between the beginning and end of courses (Hasler, \& Amichai- Hamburger, 2013).

We, both female, come from totally different backgrounds. One researcher is an Israeli Palestinian Arab who belongs to the outgroup and teaches at an Arab college in the north, and the other researcher is a religious Jew who belongs to the ingroup and teaches at a religious college in the city of Holon. Since we are both members of the TEC center, we decided to take action in an attempt to connect the different segregated religious/ethnic groups that live in Israel.

\section{Methodology}

This mixed method research combines both qualitative and quantitative methods. Mixed method research offers an insider's perspective and more depth in analyzing multidimensional contexts (Klassen \& Shane, 2007). In order to check the TEC students' attitudes, our research question was the following: Is there a significant difference between the TEC students' attitudes toward "the other" at the beginning and the end of the course? 


\section{Research Context}

The yearly online course that served as a basis for this research connects students from different colleges. The five (one Arab and four Jewish) colleges involved are situated in different areas in the country. The first college is situated in the heart of the Galilee and contains only Israeli Palestinian Arab students (Muslim, Christian, and Druze, both secular and religious). The second college is a secular Jewish college, but one-third of the students are Arab, one-third are Jewish religious, and the remaining third are Jewish secular. This college is situated in the Golan Heights. The third college is religious Jewish and is in the city of Holon in the center of Israel; it contains only Jewish female students. The fourth college in Tel Aviv is a secular college at which the students are mostly Jewish secular with a few Israeli Palestinian Arab students. The fifth college has a mixed Arab and Jewish, secular and religious, population and is located in Jerusalem. To sum up, three of the Jewish colleges contained a minority of Israeli Palestinian Arab students, one college was just Arab, and the other was just Jewish.

\section{Participants}

A total of 115 students, 11 male and 104 female, from five different colleges took part in the intercollegiate English TEC course. Students ranged from 19 to 57 years old. They were divided into 20 mixed groups in which they worked collaboratively online on different assignments. The participants included second and third year students as well as mature students returning to re-qualify as English teachers. In some colleges the course was compulsory, while in other colleges the course was an elective. Most of the students were not native speakers of English. Their mother tongues were Arabic, Hebrew, and Russian. Although 115 students took part in the course, not all the students completed all the assignments and filled in the pre and post questionnaires, hence the discrepancy between the number of students in the course and the numbers in the research data. This study was approved and supported by the Mofet Institute in Tel Aviv.

\section{Qualitative Research Factors}

The qualitative section of the study included analysis of reflective journals as well as open-ended questions in a pre-post questionnaire. The reflective journal entries were written during the course with a final reflection at the end of the learning experience. Students were prompted with key questions and guidelines that asked them to write their expectations and apprehensions at the beginning of the course and at the end of the course, as well as their attitude toward "the other," and their attitude toward collaborative e-learning. An example of the open-ended questions asked is: "How do you feel about collaborating with students from different colleges/backgrounds?" The data from the open-ended questions and the reflective journals were analyzed according to themes and categories relating to the research question. To ensure validity, we categorized the 
recurrent themes separately (Denzin \& Lincoln, 2013; Ryan \& Bernard, 2003). We then discussed and clarified the categories and quantified the qualitative responses so as to understand which themes were the most prevalent.

\section{Quantitative Research Factors}

The quantitative section of the study included closed questions in the pre and post questionnaires. Pseudonyms were used so that students could be matched in the pre and post questionnaires. The first section of the questionnaire consisted of personal information. The second part was taken from Smith's semantic list (1982) and was adapted specifically for the different groups and sects in Israel. This section of the questionnaire related to preconceived ideas about the other group (Arabs or Jews). Students were asked to rate the "other" using a 6-point bipolar (semantic differential) scale: easy to work with/not easy to work with, honest/dishonest, interesting/not interesting, prompt/tardy, trusting/untrusting, and friendly/unfriendly. One statement, for example, read: "The Jewish/ Israeli Palestinian Arab students in my group will be easy to work with [or] difficult to work with." The validity of the questionnaire was tested prior to its use by distributing it to three experts in the field; their comments were taken into consideration and changes were made accordingly.

The dependent variables in this study were students' perception of their own learning and students' attitude toward "the other." The independent variables were the following: college of affiliation (the students all belonged to different colleges that had different ideologies; although some colleges may have students from different religious backgrounds, we still see the college itself as an independent variable), age, marital status, religion, and degree of religious belief (secular, traditional, or religious).

For the quantitative data, descriptive statistics were obtained (means, variances, frequency, and standard deviations) and inferential statistical analysis was used to test the differences in attitudes between/among pre-service teachers according to their background characteristics (ANOVA, t-test). The t-test examined the difference between the different independent variables mentioned above according to the dependent variable, the students' attitude towards "the other."

\section{Qualitative Findings}

Both the open-ended questions at the beginning and at the end of the course questionnaire, as well as the student reflection journals, were analyzed by each of us independently. Ninety-six students out of the total 115 students took part in these three activities at the beginning of the course, while 80 students responded at the end of the course. A number of themes emerged. 


\section{Excitement}

A major theme that emerged from the qualitative data was a feeling of excitement about being part of a course in which students from different cultures study together (70 responses at the beginning and 75 responses at the end). This theme was prevalent among all the students, whether Israeli Palestinian Arabs or Jews, both before and after taking the course. An example of this theme is given by one student at the beginning of the course when she says:

I think this course will be my opportunity to get to know people from different backgrounds. Literature can lift the "barriers" and enable the students to open up and share their thoughts in a safe environment. I welcome the opportunity to collaborate with students from different backgrounds because I think it is something that is missing in this country.

In the middle of the year-long course, the students met face to face on neutral ground (in an academic center not connected specifically to any of the colleges). The students reflected on this meeting and again, excitement coupled with satisfaction and enjoyment were prevalent themes. Most of the students expressed how excited they were about the opportunity to meet their colleagues from other colleges and backgrounds after having worked together online without seeing pictures of one another:

I hope to meet my group and learn about new cultures. I hope that I will enjoy meeting my group and that there will be chemistry. I'm very curious to see them in real life and connect voices to faces.

This theme was also prominent in the students' reflective journals after meeting their group face to face:

I thought that the meeting was going to be tedious and boring, but luckily I was wrong. The activities were wonderful and engaging and the group members were very friendly and welcome to each other. It's funny that one can imagine someone's appearance in a certain way but in reality he looks different.

\section{Apprehension and Anxiety}

The theme of apprehension and anxiety was prevalent in the beginning of the course (22 responses), but seemed to dwindle as the course went on. Here are extracts from the beginning of the course from three journals, one from an Israeli Palestinian Arab and two from Jewish students:

On the one hand I am worried and on the other hand I am excited. (Israeli Palestinian Arab student)

I am aware of the cultural differences and hope that there will be no conflicts about irrelevant issues. (Jewish student)

Before starting the course I was really nervous about having a yearly course with Arabs. (Jewish student) 
It is clear that the fear and apprehension arose from having to cope with working with students they had never worked with or met with before, and who also came from different and conflicting backgrounds. Once they saw the other student as a person like themselves, the apprehension lessened, becoming almost non-existent. This theme of apprehension and anxiety was also prevalent among both Israeli Palestinian Arab and Jewish students when they wrote about the challenges before and after the course (A total of 29 students related to this in their journals before starting the course). Here the students clarified that they were anxious and worried that they could not be themselves and that conversations could become arguments around political issues. It is one of the reasons for their fear of working with students from another culture. A number of students clarified this by saying that the challenge was to "convince others of our opinions." Another student said she was worried about stating her true political beliefs because they "may hurt or insult a different member."

The apprehension and anxiety was not only for political reasons but also included fears of disagreements over religious topics, stereotyping, and ethnic and gender issues (13 responses at the beginning and two responses at the end). This is an extension of the political issues mentioned above. For example, one student wrote: "[My apprehension is that I will need to face] different religious views which might lead to some disagreements, not understanding or accepting someone else's opinion." At the end of the course this theme was still seen as a challenge. One student said, "I wasn't comfortable because they [the Jewish students] are very religious." Another student explained how she coped with the cultural differences by just listening politely and avoiding conflict: "I listened politely and didn't disagree. We come from different cultures and different beliefs, disagreeing with what someone deems true is pointless."

Some final anxiety-inducing factors involved technology and collaboration. These challenges revolved around the type of instruction in the course: challenges using the technology, challenges involved in collaborative learning in teams, and the fact that students worked from home; some students mentioned the difficulties of synchronous meetings.

\section{Transformation}

The most significant theme that was noted in the reflections at the end of the course is what we termed transformation: when students recognized that they had made a personal change in how they viewed the other group, Israeli Palestinian Arabs or Jews. By learning about people different from themselves and working collaboratively with them, from writing to one another to meeting face to face, students went through a process, and many favorably changed their opinion of the other group. The students felt that the course challenged them to leave their comfort zone and see things from different perspectives. This is not always easy for students but, when it occurs, there is transformation:

The course "exploring culture through literature" was one of the most special experiences I've had throughout my college years. Although it completely blew me off my comfort zone yet it was enthusiastic and challenging in the same time. I 
went through a long, big and extremely important process during this course... I also think that this course caused me to look at things differently, and see the bigger picture and it is very important.

\section{Quantitative Findings}

The quantitative part of the study included $\mathrm{n}=31$ Jewish students (mean age $=28.1$ years) and $n=21$ Israeli Palestinian Arab students (mean age $=21.7$ ). The students used pseudonyms when filling in the questionnaires. Unfortunately, some students forgot the pseudonyms they used when it was time for the post-questionnaires and therefore were unable to participate in this stage. Thus, we ended with only 56 pre-post questionnaires. The quantitative data were compiled through the use of the paired t-test. This examination shows a relationship between the student and the way new material is presented.

The difference between T1 and T2 stages (Time1 and Time 2: the different times the questionnaire was given) of the study was tested using a paired samples t-test for the whole group. In addition, a repeated measures Anova with group (culture) as an independent variable and time difference as a within-subjects independent variable was conducted.

The results of the t-test indicated that the perception towards outgroup/ingroup improved among Jewish and Israeli Palestinian Arab participants during the intervention program from 4.13 to 4.92 (see Table 1). When comparing these differences within Jewish and Israeli Palestinian Arab students separately, no significant effect was found. This finding shows an improvement in attitudes among both groups.

Table 1

Paired Samples t-test Results

\begin{tabular}{|l|c|c|c|c|c|}
\hline & & Mean & $\mathrm{N}$ & $\mathrm{SD}$ & $\mathrm{t}$ \\
\hline Attitudes toward other cultures & $\mathrm{T} 1$ & 3.76 & 56 & 0.59 & 0.325 \\
\hline & $\mathrm{T} 2$ & 3.73 & 56 & 0.62 & \\
\hline Discrimination & $\mathrm{T} 1$ & 2.20 & 56 & 0.50 & -1.423 \\
\hline & $\mathrm{T} 2$ & 2.35 & 56 & 0.69 & \\
\hline Shared activities & $\mathrm{T} 1$ & 3.74 & 56 & 1.01 & 1.213 \\
\hline & $\mathrm{T} 2$ & 3.59 & 56 & 1.18 & \\
\hline $\begin{array}{l}\text { The Jewish/ Israeli Palestinian Arab } \\
\text { students in my group will be friendly }\end{array}$ & $\mathrm{T} 1$ & 4.13 & 39 & 0.95 & $-4.38^{* * *}$ \\
\hline & $\mathrm{T} 2$ & 4.92 & 39 & 0.89 & \\
\hline Feelings toward others & $\mathrm{T} 1$ & 3.61 & 56 & 0.64 & -0.421 \\
\hline
\end{tabular}




\begin{tabular}{|l|c|c|c|c|c|}
\hline & $\mathrm{T} 2$ & 3.65 & 56 & 0.66 & \\
\hline Team work & $\mathrm{T} 1$ & 3.12 & 56 & 0.51 & -0.176 \\
\hline $\begin{array}{l}\text { Success of course depends on } \\
\text { instructors, students, teamwork }\end{array}$ & $\mathrm{T} 1$ & 4.36 & 56 & 0.58 & $2.59^{* * *}$ \\
\hline & $\mathrm{T} 2$ & 4.10 & 56 & 0.57 & \\
\hline$* * \mathrm{p}<.001$ & & & & & \\
\hline
\end{tabular}

Table 2

Means: SDs and Paired Samples t-test Comparing T1 vs. T2 in Attitudes Towards Culture

\begin{tabular}{|c|c|c|c|c|}
\hline & Mean & $\mathbf{N}$ & Std. Deviation & $\mathbf{t}$ \\
\hline $\begin{array}{l}\text { The Jewish/Israeli Palestinian Arab students in my group } \\
\text { will be easy to work with }\end{array}$ & 4.23 & 39 & 1.111 & \multirow{2}{*}{$-4.03^{* * *}$} \\
\hline $\begin{array}{l}\text { The Jewish/Israeli Palestinian Arab students in my group } \\
\text { were easy to work with }\end{array}$ & 5.13 & 39 & 1.08 & \\
\hline $\begin{array}{l}\text { The Jewish/Israeli Palestinian Arab students in my group } \\
\text { will be friendly }\end{array}$ & 4.49 & 39 & 1.144 & \multirow{2}{*}{$-4.64^{* * *}$} \\
\hline Friendly & 5.44 & 39 & 0.852 & \\
\hline $\begin{array}{l}\text { The Jewish/Israeli Palestinian Arab students in my group } \\
\text { will be honest }\end{array}$ & 4.18 & 39 & 1.189 & $-5.06^{* * *}$ \\
\hline Honest & 5.23 & 39 & 1.038 & \\
\hline $\begin{array}{l}\text { The Jewish/Israeli Palestinian Arab students in my group } \\
\text { will be prompt }\end{array}$ & 3.77 & 39 & 1.287 & $-3.89^{* * *}$ \\
\hline Prompt & 4.64 & 39 & 1.328 & \\
\hline $\begin{array}{l}\text { The Jewish/Israeli Palestinian Arab students in my group } \\
\text { will be interesting }\end{array}$ & 4.15 & 39 & 1.329 & $-2.53^{*}$ \\
\hline Interesting & 4.79 & 39 & 1.341 & \\
\hline $\begin{array}{l}\text { The Jewish/Israeli Palestinian Arab students in my group } \\
\text { will be willing to invest effort }\end{array}$ & 4.18 & 39 & 1.254 & $-2.13^{*}$ \\
\hline Willing to invest effort & 4.74 & 39 & 1.292 & \\
\hline $\begin{array}{l}\text { The Jewish/Israeli Palestinian Arab students in my group } \\
\text { will be willing to compromise }\end{array}$ & 4.13 & 39 & 1.031 & $-4.14^{* * *}$ \\
\hline Willing to compromise & 5.03 & 39 & 1.112 & \\
\hline The Jewish/Israeli Palestinian Arab students in my group & 4.23 & 39 & 1.18 & -1.51 \\
\hline
\end{tabular}




\begin{tabular}{|l|c|c|c|c|}
\hline have a sense of humor & & & & \\
\hline Have a sense of humor & 4.67 & 39 & 1.457 & \\
\hline $\begin{array}{l}\text { The Jewish/Israeli Palestinian Arab students in my group } \\
\text { good/fun to work with }\end{array}$ & 4.22 & 37 & 1.109 & -1.86 \\
\hline Good/fun to work with & 4.73 & 37 & 1.347 & \\
\hline $\begin{array}{l}\text { The Jewish/Israeli Palestinian Arab students in my group } \\
\text { Agree/Disagree about my ideas on the conflict }\end{array}$ & 3.7 & 37 & 0.968 & $-4.88^{* * *}$ \\
\hline Agree with my ideas on the subjects & 4.73 & 37 & 0.902 & \\
\hline${ }^{*} \mathrm{p}<.05 ;{ }^{* *} \mathrm{p}<.001$ & & & & \\
\hline
\end{tabular}

\section{Discussion}

A number of results warrant discussion. First, our quantitative results show that the perception towards students from another culture (Israeli Palestinian Arabs and Jews) improved significantly during the intervention program among both Jewish and Israeli Palestinian Arab participants, from 4.13 to 4.92. In all of the questions except for the question asking if they expected their colleagues in their group to have a sense of humor and be fun to work with, the pre and post results were significant. This shows that the students had preconceived, possibly stereotypical attitudes of the other group, but after taking the course, their attitudes to the other changed significantly.

Secondly, from the qualitative data, it was evident that many students felt apprehensive about working with Israeli Palestinian Arab/Jewish students before they got to know each other and started to work together. These feelings are shown in the literature as situations in which segregation from another culture can cause fear and mistrust (Žeželj et al., 2017). Many students were apprehensive at the outset of the course, although the majority were excited and felt that the course was important. When looking at the students' reflections, the process the students went through to relieve this apprehension is evident. This is summarized by one of the students in the final reflection:

Before starting the course I was really nervous about having a yearly course with Arabs. I thought that it is going to be a waste of time! I'm not going to understand them and not going to be their friends, so why should we do it?!

In fact, at the end of the course only three students expressed apprehensive concerns, whereas at the beginning of the course 22 students showed different signs of anxiety. These findings are in line with the contact hypothesis, which claims that if four conditions are adhered to there will be successful group contact. The course studied had these four conditions as well as the opportunity of making friends, the condition added by Pettigrew (Allport, 1954; Pettigrew, 1998; White \& Abu-Rayya, 2012).

The apprehension at the beginning of the course was caused by fear of potential conflicts around political differences and different narratives (Wojcieszak \& Mutz, 2009; 
Žeželj et al., 2017). Initially many students (29), both Israeli Palestinian Arabs and Jews, were worried about political conflicts because of differences in political orientation. However, at the end of the course, this was seen to be a challenge by only two students. Obviously something had happened in the interim period to make this transformation. It was probably due both to the content of the course, which was learning through literature about the other culture, incorporating the narrative approach where students listened to the narrative of the other participants, and to the model used to build empathy gradually between the group members (Hoter, Shonfeld \& Ganayem, 2009).

Both the qualitative and quantitative data show the change from the beginning to the end of the course. The qualitative data show the process of change from anxiety to feeling comfortable with the students from other, often conflicting, cultures. The connection between the students from the different cultures progressed on a continuum in accordance with the TEC Model (Walther et al., 2015). During the course, the students bonded gradually around the assignments. They first wrote to each other--they did not see photographs of one another--and were able to build up a relationship and understanding through writing and then through speaking. It was only at the end of the first semester that the students saw pictures of one another and met face to face. This face-to-face meeting was an important point in the process the students went through. As can be seen in the qualitative results, the theme that emerged before the meeting was excitement; after the meeting, the themes were satisfaction and enjoyment.

Other challenges that were mentioned were technical issues and teamwork. Some students foresaw these issues as potentially problematic from the beginning, but by the end of the course these themes were prominent. Technical issues are inherent in any online course using a combination of advanced technologies, and sufficient technical support is needed for the teachers and the students. Connecting to online sessions was sometimes problematic, and some of the technologies used were new and difficult for some of the students. Generally there were problems with connections to the Internet and use of microphones in the online sessions. These problems and challenges seem to be inherent in many online courses (Helm, 2015; O'Dowd \& Ritter, 2006).

The teamwork aspect of the course was also not always easy. There are often weak links in a group which slow down the work of the group, and rules need to be adhered to in order to improve the collaboration and communication (Walther \& Bunz, 2005). Some students stated that they prefer to work alone. However, the purpose of the course was to make the students work in small groups to learn about and from one another.

\section{Implications}

The general implications of the study seem to suggest that a gradual model to get to know and develop empathy with the outgroup through collaborative online learning, as well as the content of the course being about Arab Palestinian and Jewish literature, can change attitudes of students towards the outgroup. This type of course in which technology is used to facilitate interaction and collaboration can be used to build bridges 
between other cultures in conflict or post-conflict areas in the world. In addition, it can aid the development of understanding between different races, religions, and cultures.

Ethical issues were considered while conducting this research. Care was taken to ensure that the questionnaires were anonymous. Pseudonyms were used so that students could be matched in the pre and post questionnaires. However, in addition to the questionnaires, the students were required to submit reflective journal entries throughout the year. These were graded and were not anonymous. This fact may have affected the accuracy and honestly of the students' responses. Another ethical issue arises from the fact that the researchers were also members of the teaching team for the course. On the one hand, as teachers we had a more in-depth understanding of the material and the TEC model. However, there could also be a conflict of interests due to our personal involvement in the course.

\section{Limitations}

There were a number of limitations to this study. First, our questionnaire did not specifically test for anxiety. This is something that should be considered for further research (Shapira et al., 2016; Žeželj et al., 2017). Second, not all of the students filled in the questionnaire because this was an optional element in the course. More creative ways need to be developed to encourage the students to fill in their questionnaires. Third, the reflective journal was compulsory and not anonymous. This could have affected the students' responses; they may have written more favorably in order to obtain a higher grade.

\section{Conclusion}

The implications of this research seem to show that reticence and fear about working in virtual groups with people from different and even conflicting cultures is the main barrier to working together. Much care needs to be taken in planning collaborative work in virtual groups to lessen this fear as early on in the intervention as possible. We recommend that other teacher training colleges both in Israel and around the globe adopt this online course model, first to learn about the other culture and also to reduce anxiety towards the outgroup.

\section{References}

Aberson, C. L., Shoemaker, C., \& Tomolillo, C. (2004). Implicit bias and contact: The role of interethnic friendships. Journal of Social Psychology, 144, 335-347.

Abrams, D., Hogg, M., \& Marques, J. (2005). The psychology of inclusion and exclusion. New York, NY: Psychology Press. 
Allport, G. W. (1954). The nature of prejudice. New York, NY: Addison-Wesley.

Amichai-Hamburger, Y., \& McKenna, K. Y. A. (2006). The contact hypothesis reconsidered: Interacting via the internet. Journal of Computer-Mediated Communication. https://doi.org/10.1111/j.1083-6101.2006.00037.x

Amir, Y. (1969). Contact hypothesis in ethnic relations. Psychological Bulletin, 71, 319342.

Banks, J. (2001). Citizenship education and diversity: Implications for teacher education. Journal of Teacher Education, 52, (1), 5-16.

Banks, J. A. (Ed.). (2009). The Routledge international companion to multicultural education. New York, NY: Routledge.

Batson, C. D., \& Ahmad, N. Y. (2009). Using empathy to improve intergroup attitudes and relations. Social Issues and Policy Review, 3(1), 141-177.

Bollati, A. (2002). Creating a learning community through electronic journals. The Internet TESL Journal. Retrieved from http://iteslj.org/Techniques/Bollati-Journaling.html

Causey, V., Thomas, C., \& Armento, B. (2000). Cultural diversity is basically a foreign term to me: The challenges of diversity for preservice teacher education. Teaching and Teacher Education, 16, 33-45.

Denzin, N. K., \& Lincoln, Y. S. (2013). Introduction: The discipline and practice of qualitative research. In N. K. Denzin \& Y. S. Lincoln (Eds.), Strategies of qualitative inquiry (pp. 1-42). Thousand Oaks, CA: Sage.

Dessel, A. B., \& Ali, N. (2012). Arab/Jewish intergroup dialogue courses: Building communication skills, relationships, and social justice. Small Group Research, 43(5), 559-586.

Dewiyanti, S., Brand-Gruwel, S., Jochems, W., \& Broers, N. (2007). Students' experiences with collaborative learning in asynchronous computer-supported collaborative learning environments. Computers in Human Behavior, 23, 496-514.

O'Dowd, R. O., \& Ritter, M. (2006). Understanding and working with "failed communication" in telecollaborative exchanges, CALICO Journal, 23(3), 623-642.

Foroutan, M., \& Noordin, N. (2012). Effect of dialogue journal writing through the use of conventional tools and e-mail on writing anxiety in the ESL context. English Language Teaching, 5(1), 10-19. doi: 10.5539/elt.v5n1p10

Greenland, K., Xenias, D., \& Maio, G. (2012). Intergroup anxiety from the self and other: Evidence from self-report, physiological effects, and real interactions. European Journal of Social Psychology, 42(2), 150-163.

Hamm, J., Brown, B., \& Heck. H, (2005). Bridging the ethnic divide: Student and school characteristics in African American, Asian-Descent, Latino, and White adolescents' cross-ethnic friend nominations. Journal of Research on Adolescence, 15(1), 21-46.

Helm, F. (2015). The practices and challenges of telecollaboration in higher education in Europe. Language Learning \& Technology, 19(2), 197-217. Retrieved from http://llt.msu.edu/issues/june2015/helm.pdf 
Harasim, L. (Ed.). (2012). Learning theory and online technologies. New York, NY: Routledge.

Hasler, B. S., \& Amichai-Hamburger, Y. (2013). Online intergroup contact. In Y. AmichaiHamburger (Ed.), The social net: Understanding our online behavior (pp. 220252). New York, NY: Oxford University Press.

Hill, I. (2007). Multicultural and intercultural education: Never the twain shall meet? Review of Education, 53, 245-264.

Horenczyk, G., \& Tatar, M. (2004). Education in a plural society or multicultural education? The views of Israeli Arab and Jewish school counsellors. Journal of Peace Education, 1(2), 191-204.

Hoter, E. (2006). Building community or a collaborative project? Connecting the hearing and non-hearing communities. Information Technology, Education and Society, 7(1), 45-58.

Hoter, E., Shonfeld, M., \& Ganayim, A. (2009). Information and communication technology (ICT) in the service of multiculturalism. The International Review of Research in Open and Distance Learning, 10(2), 1-7.

Hoter, E., Shonfeld, M. \& Ganayem, A.N. (2012). TEC Center: Linking technology, education and cultural diversity. I-manager's Journal of Educational Technology, 9(1), 15-22.

Jobling, A., \& Moni, K. B. (2004). "I never imagined I'd have to teach these children": Providing authentic learning experiences for secondary pre-service teachers in teaching students with special needs. Asia-Pacific Journal of Teacher Education, $32(1), 5-22$.

Klassen, R., \& Shane, L. (2007). Self-efficacy from the perspective of adolescents with LD and their specialist teachers. Journal of Learning Disabilities, 40(6), 494-507.

Kreijns, K., Kirschner, P. A., Jochems, W., \& Van Buuren, H. (2004). Determining sociability, social space, and social presence in (a)synchronous collaborative groups. CyberPsychology \& Behavior, 7(2), 155-172.

Maoz, I. (2002). Is there contact at all? Intergroup interaction in planned contact interventions between Jews and Arabs in Israel. International Journal of Intercultural Relations, 26(2), 185-197. http://dx.doi.org/10.1016/S0147-1767(01)00046-3

Maoz, I. (2011). Does contact work in protracted asymmetrical conflict? Appraising 20 years of reconciliation-aimed encounters between Israeli Jews and Palestinians. Journal of Peace Research, 48(1), 115-125.

Mollov, B. (2006, June). Results of Israeli and Palestinian student interactions in CMC: An analysis of attitude changes toward conflicting parties. Paper presented at the Annual Meeting of the International Communications Association, Dresden, Germany.

Nguyen-Phuong-Mai, M. (2017). Intercultural communication: An interdisciplinary approach: When neurons, genes, and evolution joined the discourse. Amsterdam, The Netherlands: Amsterdam University Press. 
Page-Gould, E., Mendoza-Denton, R., \& Tropp, L. R. (2008). With a little help from my cross-group friend: Reducing anxiety in intergroup contexts through cross-group friendship. Journal of Personality and Social Psychology, 95, 1080-1094. https://dx.doi.org/10.1037/0022-3514.95.5.1080

Pettigrew, T. F. (1998). Intergroup contact theory. Annual Review of Psychology, 49(1), 65-85. https://doi.org/10.1146/annurev.psych.49.1.65

Pettigrew, T. F., \& Tropp, L. R. (2008). How does intergroup contact reduce prejudice? Meta-analytic tests of three mediators. European Journal of Social Psychology, 38, 922-934. https://dx.doi.org/10.1002/ejsp.504

Razak, R. A., \& Asmawi, A. (2004). The use of dialogue journal through e-mail technology in developing writing interest and skills. Malaysian Online Journal of Instructional Technology, 1(2), 14-23.

Rosen, Y., \& Perkins, D. (2013). Shallow roots require constant watering: The challenge of sustained impact in educational programs. International Journal of Higher Education, 2(4), 91-100.

Ryan, G., \& Bernard. H. R. (2003). Techniques to Identify themes. Field Methods, 15, 85110. doi: $10.1177 / 1525822 \times 02239569$

Said, E. W. (1978). Orientalism. New York, NY: Penguin.

Salomon, G. (2013). Lessons from research on peace education in Israel/Palestine. Asian Journal of Peacebuilding, 1 (1), 1-15.

Shapira, N., Kupermintz, H., \& Kali, Y. (2016). Design principles for promoting intergroup empathy in online environments. Interdisciplinary Journal of e-Skills and Life Long Learning, 12(12), 225-246. Retrieved from http://www.informingscience.org/ Publications/3605

Shonfeld, M., Hoter, E., \& Ganayem, A. (2013). Connecting cultures in conflict through ICT in Israel. In R. S. P. Austin \& W. J. Hunter (Eds.), Online learning and community cohesion: Linking schools (pp. 42-58). New York, NY: Routledge.

Smith, R.W. (1982). Improving intergroup relations: The impact of two types of small group encounters between Jewish and Arab Israeli youth. Unpublished doctoral dissertation, Temple University, Philadelphia, PA.

Smith, R.W. (2000). The influence of teacher background on the inclusion of multicultural education: A case study of two contrasts. The Urban Review, 52(2), 155-176.

State Comptroller Special Report (2016). Co-existence and fighting racism in Israel. Jerusalem, Israel: Author.

Stephan, W. G., \& Stephan, C. W. (1985). Intergroup anxiety. Journal of Social Issues, 41, 157-175. https://doi.org/10.1111/j.1540-4560.1985.tb01134.x

Turner, R. N., Tam, T., Hewstone, M., Kenworthy, J., \& Cairns, E. (2013). Contact between Catholic and Protestant schoolchildren in Northern Ireland. Journal of Applied Social Psychology, 43, 216-228. https://doi.org/10.1111/jasp.12018 
Turner, R. N., \& Cameron, L. (2016). Confidence in contact: A new perspective on promoting cross-group friendship among children and adolescents. Social Issues and Policy Review, 10(1), 212-246. doi: 10.1111/sipr.12023

Valentine, S., (2006). Addressing diversity in teacher education programs. Education, 127(2), 196-202.

Wallace, J. D., \& Rogers, R. K (2011). Predictors of technology integration in education: A study of anxiety and innovativeness in teacher preparation. Journal of Literacy and Technology, 2, 29-61.

Walther, J. B., Hoter, E., Ganayem, A., \& Shonfeld, M. (2015). Computer-mediated communication and the reduction of prejudice: A controlled longitudinal field experiment among Jews and Arabs in Israel. Computers in Human Behavior, 52, 550-558.

Walther, J. B., \& Bunz, U. (2005). The rules of virtual groups: Trust, liking, and performance in computer-mediated communication. Journal of Communication, 55, 828-846.

Walther, J. B., \& Carr, C. T. ( 2010 ). Internet interaction and intergroup dynamics. In H. Giles, S. Reid , \& J. Harwood (Eds.), The dynamics of intergroup communication (pp. $209-220$ ). New York, NY: Peter Lang.

White, F. A., \& Abu-Rayya, H. M. (2012). A dual identity-electronic contact (DIEC) experiment promoting short- and long-term intergroup harmony. Journal of Experimental Social Psychology, 48(3), 597-608. https://doi.org/10.1016/ j.jesp.2012.01.007

Wojcieszak, M. E., \& Mutz, D. C. (2009). Online groups and political discourse: Do online discussion spaces facilitate exposure to political disagreement? Journal of Communication, 59(1), 40-56. https://doi.org/10.1111/j.1460-2466.2008.01403

Yazbak Abu Ahmad, M., Dessel, A., \& Ali. N. (2018). Arab American college students: What predicts their engagement with the Israeli/Palestinian conflict? Peace and Conflict Studies Journal, 25(2), 1-31.

Yazbak Abu Ahmad, M. \& Yahav, A. (2014). Humanizing the other. Teacher Education Advancement Network (TEAN), 6(1), 41-54.

Yogev, A. (2001). בחברה ערכי חינוך גישות פלורסטית (Approaches to values in a pluralistic society). In S. Eiram, A. Skolbikov, \& Schechter (Eds.). Tsomet, values and education in the Israeli society (pp. 355-379). Jerusalem, Israel: The Ministry of Education.

Žeželj, I. L., loannou, M., Franc, R., Psaltis, C., \& Martinovic, B. (2017). The role of interethnic online friendships in prejudice reduction in post-conflict societies: Evidence from Serbia, Croatia and Cyprus. Computers in Human Behavior, 76, 386-395. https://doi.org/10.1016/j.chb.2017.07.041 


\section{Author Contact}

Manal Yazbak Abu Ahmad: manalyazbak@gmail.com

Sakhnin College for Teacher Education, POB 100, Sakhnin 20173, Israel

Elaine Hoter: ehoter@gmail.com

Talpiot Academic College, 7 Yotvata, HOLON 5850018, Israel 